\title{
Pengembangan Sistem Informasi Perpustakaan Menggunakan Teknologi Google Web Toolkit (GWT)
}

\author{
Winangsari Pradani ${ }^{1}$, Ade Jamal ${ }^{1}$, Arie Wahyu Triansyah ${ }^{1}$, Annisa Utami ${ }^{1}$ \\ ${ }^{1}$ Program Studi Teknik Informatika, Fakultas Sains dan Teknologi, Universitas Al Azhar Indonesia, \\ Kompleks Masjid Agung Al Azhar, Jakarta Selatan, 12110, Indonesia \\ E-mail : winangsari@uai.ac.id, adja@uai.ac.id
}

\begin{abstract}
Abstrak - Stock opname merupakan salah satu kegiatan penting pada perpustakaan dalam pemeliharaan koleksi pustaka. Kegiatan stock opname adalah melakukan pencocokan data antara koleksi pustaka yang ada di rak-rak buku dengan pangkalan data yang dimiliki perpustakaan. Pada saat ini kegiatan stock opname pada Perpustakaan SMP/SMA AlAzhar Kebayoran Baru belum dilaksanakan secara rutin karena keterbatasan tenaga SDM. Perpustakaan SMP/SMA Al Azhar telah menggunakan aplikasi Senayan Library Management System (SLiMs) yang bersifat open source. Di lain pihak, Teknik Informatika UAI juga memiliki satu sistem aplikasi perpustakaan yaitu Sistem Informasi Perpustakaan berbasis desktop (SIAP). Modul mobile stock opname telah ada di aplikasi SIAP. Dalam kegiatan penelitian ini modul stock opname SIAP akan ditempelkan kepada sistem SLiMS. Dengan modul aplikasi mobile stock opname yang ada pada handset atau komputer tablet, pustakawan dapat langsung memasukkan data hasil pemeriksaan pada saat kegiatan berlangsung. Langkah mencetak daftar koleksi dan pencatatan manual tidak diperlukan lagi. Jika sebelumnya kegiatan stock opname dilakukan 3 langkah, dengan sistem baru menjadi 1 langkah. Waktu yang dibutuhkan untuk pencatatan berkurang hingga tinggal $50 \%$ dari waktu semula.
\end{abstract}

Abstract - Stock opname is one of the important activities of the library in the maintenance of library collections. Stock opname is doing data matching between the existing library collections in bookshelves with a database owned by the library. At this time, stock opname actifity in the library SMP / SMA AlAzhar Kebayoran Baru has not been implemented on a regular basis due to limited human resources personnel. Library SMP / SMA Al Azhar have used the application Senayan Library Management System (SLiMs), which is open source. On the other hand, Information Engineering UAI also has a library application system is Sistem Informasi Perpustakaan berbasis desktop (SIAP). Mobile module inventory check has existed in the SIAP. In this research activity, stock opname module in SIAP will be attached to the SLiMs. With the mobile application modules existing inventory check on the handset or tablet computer, librarians can directly enter data at the time of examination activities take place. Step print a list of collection and manual recording is not required anymore. If previous activities carried out stock taking three steps, with the new system into one step. The time required for recording reduced to $50 \%$ of the original time.

Keywords - Stock Opname, DAO, SLiMS

\section{PENDAHULUAN}

$\mathrm{P}$ ermasalahan yang dihadapi oleh perpustakaan SMP/SMA Al Azhar Kebayoran Baru adalah pendataan koleksi pustaka (stock opname) tidak dilaksanakan secara rutin, disebabkan jumlah koleksi yang sangat banyak serta pada saat yang sama juga berlangsung kegiatan peminjaman dan pengembalian koleksi pustaka. Masalah lain yang sering dihadapi adalah seringkali anggota atau pengunjung perpustakaan kesulitan untuk melakukan pencarian koleksi, disebabkan tidak akuratnya data yang disediakan.

Terdapat dua aplikasi perpustakaan yaitu SLiMs dan SIAP yang memiliki basisdata yang berbeda dalam hal nama tabel dan atribut dalam tabel. 
Perbedaannya meliputi kode koleksi pustaka pada SIAP adalah kode_koleksi dan kode_klasifikasi, sedangkan pada SLiMs adalah item_code dan call_number, serta data stock opname pada SIAP ditampung pada satu tabel yaitu tabel koleksi, sedangkan pada SLiMs pada dua tabel yaitu tabel stock_take dan stock_take_item.

Tujuan dari kegiatan penelitian ini adalah untuk mengkaji penyesuaian yang harus dilakukan agar modul mobile stock opname SIAP bisa dijalankan pada SLiMs. Hasil kajian adalah berupa disain dan petunjuk yang dapat diikuti untuk tahap programming. Sistem operasi mobile yang dipilih adalah android dan teknologi manipulasi basisdata yang dipakai adalah DAO.

\section{KERANGKA TEORI}

\section{Google Web Toolkit (GWT)}

GWT adalah toolkit pengembang aplikasi web menggunakan Java yang kemudian dapat diubah ke JavaScript. Dengan menggunakan GWT, dimungkinkan untuk membuat interface application menggunakan Java, kemudian dengan mengubah source code Java tersebut ke JavaScript maka aplikasi tersebut dapat berjalan di semua browser utama. Dengan demikian, proses debug aplikasi dalam IDE dilakukan seperti men-debug aplikasi Java "biasa". Hal ini dapat dilakukan melalui sebuah plugin pengembang browser, yang meliputi Java bytecode dan JavaScript browser. Setelah siap, kode Java GWT dikompilasi ke JavaScript. Lebih tepatnya, antarmuka aplikasi yang dikompilasi terdiri atas JavaScript, HTML, dan XML. Ada beberapa keuntungan saat proses kompilasi dalam hal efisiensi, keamanan, dan kompatibilitas browser.

\section{Data Access Object (DAO)}

DAO merupakan konsep disain yang digunakan untuk membangun sebuah sistem berbasis basisdata. Dengan menggunakan DAO pengembang akan memecah program menjadi kelas-kelas kecil dimana kelas-kelas tersebut saling berinteraksi. Maka, kesalahan di satu bagian program dapat dikoreksi tanpa perlu mempertimbangkan bagian-bagian lainnya.

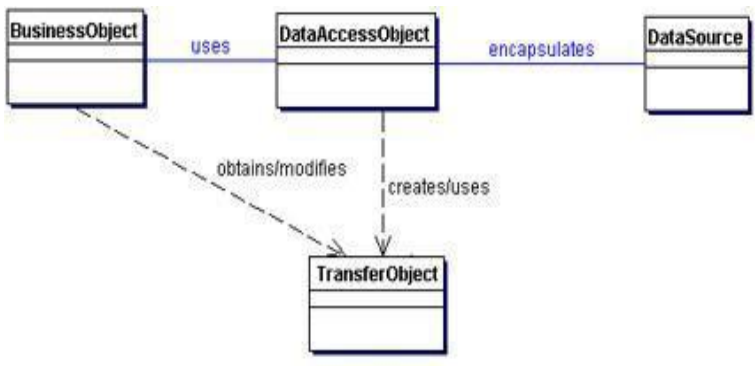

Gambar 1. Data Access Object

Awal mula pengembangan DAO didasarkan pada banyaknya aplikasi platform Java Enterprise Edition (J2EE) yang memerlukan persistence data atau data tetap yang disimpan dan dapat dipergunakan kembali pada beberapa bagian. Mekanisme penyimpanan data ini diimplementasikan dengan cara berbeda-beda.

Di Java, aplikasi dapat menggunakan The Java Database Connectivity (JDBC) untuk mengakses data yang terdapat di dalam Relational Database Management System (RDBMS). Application Programming Interface (API) dari JDBC memungkinkan standarisasi akses dan manipulasi dari data di persistent storage, seperti relational database. API dari JDBC juga memungkinkan aplikasi J2EE untuk menggunakan perintahperintah Structured Query Language (SQL), yang merupakan alat standar untuk mengakses tabel RDBMS. Gambar 1 merupakan konsep desain DAO secara umum.

\section{Senayan Library Management System (SliMS)}

SLiMS adalah perangkat lunak sistem manajemen perpustakaan (library management system) yang bersifat open source di bawah lisensi GPL v3. Aplikasi ini pertama kali dikembangkan dan digunakan oleh Perpustakaan Kementerian Pendidikan Nasional, Pusat Informasi dan Hubungan Masyarakat, Kementerian Pendidikan Nasional. Seiring perkembangan waktu, aplikasi ini kemudian dikembangkan oleh komunitas pengguna dan penggiat SLiMS.

Aplikasi SLiMS dibangun dengan menggunakan PHP, basis data MySQL, dan pengontrol versi Git. Pada tahun 2009, SLiMS mendapat penghargaan tingkat pertama dalam ajang INAICTA 2009 untuk kategori open source. Saat ini SLiMS telah digunakan luas oleh berbagai perpustakaan, baik di dalam maupun luar negeri. Perangkat lunak SLiMS dapat diunduh di http://perpustakaan.kemdiknas.go.id/senayan atau http://slims.web.id. 
Fitur SLiMS meliputi:

1) Online Public Access Catalog (OPAC) dengan pembuatan thumbnail yang di generate onthefly.

2) Thumbnail berguna untuk menampilkan cover buku.

3) Mode penelusuran tersedia untuk yang sederhana (Simple Search) dan tingkat lanjut (Advanced Search).

4) Detail record juga tersedia format XML (Extensible Markup Language) untuk kebutuhan web service.

5) Manajemen data bibliografi yang e_sien meminimalisasi redundansi data.

6) Manajemen master_le untuk data referensial seperti GMD (General Material Designation), Tipe Koleksi, Penerbit, Pengarang, Lokasi, Supplier, dan lain-lain.

7) Sirkulasi dengan _tur: Transaksi peminjaman, pengembalian, reservasi koleksi, aturan peminjaman yang_eksibel, Informasi keterlambatan dan denda.

8) Manajemen keanggotaan.

9) Stock opname/stocktake.

10) Laporan dan Statistik.

11) Pengelolaan terbitan berkala (Kardex).

12) Dukungan pengelolaan dokumen multimedia (_v,.mp3) dan dokumen digital lainnya. Khusus untuk pdf dalam bentuk streaming.

13) Senayan mendukung beragam format bahasa termasuk bahasa yang tidak menggunakan penulisan selain latin.

14) Menyediakan berbagai bahasa pengantar (Indonesia, Inggris, Spanyol, Arab, Jerman, Thailand).

15) Dukungan Modul Union Catalog Service.

16) Counter Pengunjung perpustakaan.

17) Member Area untuk melihat koleksi yang sedang dipinjam oleh anggota.

18) Modul sistem dengan _tur: Kon_gurasi sistem global, Manajemen modul,

19) Manajemen User (Staf Perpustakaan) dan grup, Pengaturan hari libur, Pem buatan barcode otomatis, Utilitas untuk backup.

20) Copy cataloguing dengan protokol z39.50 dan $\mathrm{p} 2 \mathrm{p}$ service.

Pemberitahuan $\begin{aligned} & \text { surat } \\ & \text { peminjaman melalui }\end{aligned}$ e-mail dengan
menggunakan mail server.

\section{Stock Opname}

Stock opname merupakan salah satu kegiatan perpustakaan dalam pemeliharan koleksi pustaka.
Kegiatan stock opname adalah melakukan pencocokan data antara koleksi pustaka yang ada di rak-rak buku dengan pangkalan data yang dimiliki perpustakaan. Perpustakaan SMP/SMA Islam Al Azhar Kebayoran Baru sudah mempunyai sistem perpustakaan namun sistem yang ada masih belum optimal.

Saat stock opname dilakukan, pustakawan atau petugas perpustakaan terlebih dahulu melakukan print out seluruh data koleksi pustaka yang ada pada pangkalan data. Hasil dari print out tersebut akan dijadikan acuan data untuk melakukan stock opname. Kemudian pustakawan akan melakukan survey ke lokasi rak-rak koleksi seluruh perpustakaan untuk memeriksa kondisi fisik koleksi serta memastikan keberadaan koleksi yang terdaftar pada print out tersebut. Setelah itu koleksi yang sudah diperiksa akan dicatat kembali kedalam print out tersebut. Ada beberapa status yang disediakan SLiMS saat melakukan pencatatan hasil stock opname, yaitu Exist (ada), Loan (dipinjam), Missing (Hilang) dan Repair (Perbaikan).

Status tersebut nantinya akan menjadi acuan oleh pustakawan, menentukan koleksi mana saja yang boleh dipinjamkan atau tidak (sirkulasi), serta menjadi bahan pertimbangan saat melakukan pengadaan koleksi baru. Setelah melakukan stock opname dan pencatatan, kemudian data yang didapatkan akan di-input kedalam sistem satu persatu secara manual sehingga memakan waktu yang cukup lama (Gambar 2).

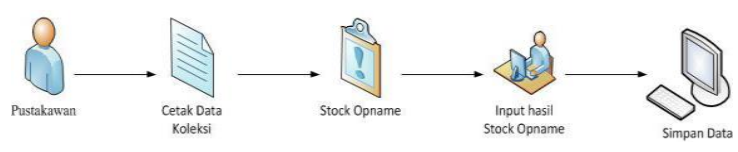

Gambar 2. Proses Stock Opname

\section{Android}

Android adalah sebuah sistem operasi untuk mobile yang menggunakan kernel dari linux yang mencakup sistem operasi, middleware dan aplikasi. Android merupakan perangkat open source yaitu pengembang bebas mengembangkan aplikasi android sesuai dengan kebutuhan.

Pengembang memiliki beberapa pilihan ketika membuat aplikasi yang berbasis android. Sebagian besar pengembang menggunakan 
Eclipse yang tersedia secara bebas untuk merancang dan mengembangkan aplikasi Android. Eclipse adalah IDE yang paling popular untuk pengembangan Android. Selain itu, Eclipse juga mendapat dukungan langsung dari Google untuk menjadi IDE pengembangan aplikasi android, hal ini terbukti dengan adanya penambahan plugins untuk eclipse dalam membuat project android, plugins tersebut dapat langsung di download dari situs Google.

\section{Use Case Diagram}

Use case diagram adalah diagram yang menggambarkan fungsionalitas suatu sistem atau kelas. Use case juga menunjukkan bagaimana sistem tersebut berinteraksi dengan use case lainnya dan bagaiman mereka terkait dengan aktor. Use case diagram menunjukkan fungsionalitas yang diharapkan dari sebuah sistem. Yang menekankan pada apa yang dapat diperbuat oleh sistem. Sebuah use case merepresentasikan sebuah interaksi antara aktor dengan sistem. Misalnya proses pendaftaran anggota baru, proses peminjaman buku, dan sebagainya.

Komponen-komponen yang menjadi pembentuk Use Case Diagram adalah actor dan use case. Actor merepresentasikan seseorang atau sesuatu (seperti perangkat, sistem lain) yang berinteraksi dengan sistem. Sebuah actor mungkin hanya memberikan informasi kepada sistem (input), hanya menerima informasi dari sistem (output) atau keduanya menerima, dan memberi informasi pada sistem (input-output). Actor digambarkan dengan stick man.

Use case adalah gambaran fungsionalitas dari suatu sistem, sehingga customer atau pengguna sistem paham dan mengerti mengenai kegunaan sistem yang akan dibangun. Use case digambarkan dengan lingkaran oval.

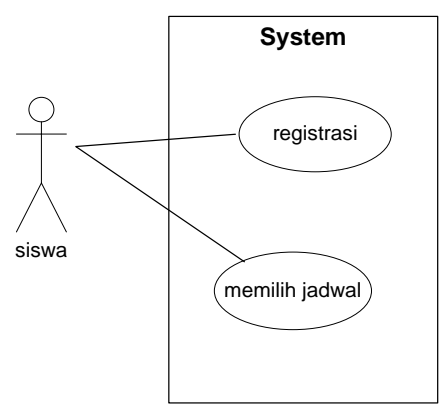

Gambar 3. Use Case Diagram
Gambar 3 menunjukkan diagram use case yang di dalamnya terdapat aktor dan use case.

\section{Activity Diagram}

Activity diagram adalah teknik untuk mendeskripsikan logika prosedural, proses bisnis dan aliran kerja dalam banyak kasus. Activity diagram menggambarkan berbagai alir aktivitas dalam sistem yang sedang dirancang, bagaimana masing-masing alir berawal, hasil akhir yang mungkin terjadi, dan bagaimana mereka berakhir. Activity diagram juga dapat menggambarkan proses paralel yang mungkin terjadi pada beberapa eksekusi. Gambar 4 menunjukkan contoh activity diagram.

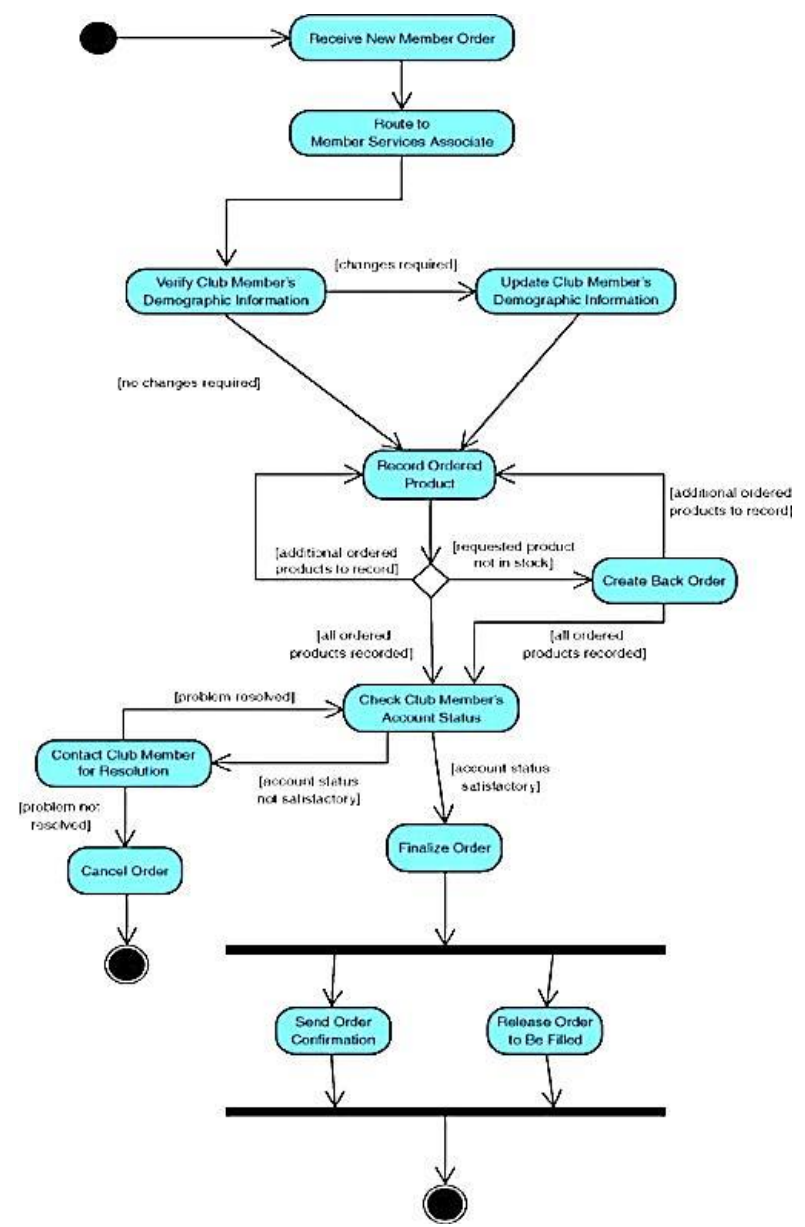

Gambar 4. Activity Diagram

\section{Logical Record Structure (LRS)}

LRS adalah representasi dari struktur recordrecord pada tabel-tabel yang terbentuk dari hasil antar himpunan entitas. Gambar 5 adalah contoh LRS. 


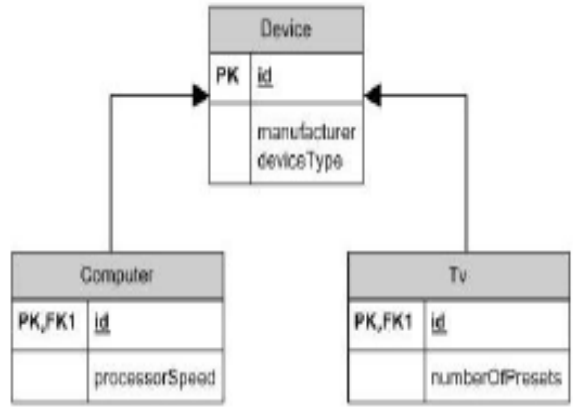

Gambar 5. Logical Record Structure

\section{METODE PENELITIAN}

Pengembangan sistem akan dilakukan dalam beberapa tahapan, yakni:

\section{Identifikasi dan Analisis Sistem}

Kebutuhan sistem digali dengan cara mewawancarai pustakawan, kemudian dibuatlah beberapa model yang menggambarkan sistem yang dapat memenuhi kebutuhan tersebut, yaitu pemodelan data yang meliputi Entity Relationship Diagram (ERD) dan Logical Structure Record (LRS) serta pemodelan proses Usecase Diagram.

\section{Disain Sistem}

Dengan menggunakan pemodelan sistem yang telah dibuat sebelumnya, maka dibuatkan disain sistem informasi berdasarkan pemodelan tersebut seperti disain form dan laporan (report), disain antarmuka dan dialog (message), disain basis data dan file (framework), disain proses (struktur proses).

\section{Implementasi Sistem}

Pada tahap ini sistem akan dibuat dan diuji berdasarkan disain pada langkah ke-2. Beberapa hal yang dilakukan diantaranya pemrograman dan pengetesan perangkat lunak (software), Alpha testing (error testing ketika sistem digabungkan dengan antarmuka user oleh software tester), Beta testing (testing dengan lingkungan dan data sebenarnya), Konversi sistem yaitu mengaplikasikan perangkat lunak pada lingkungan yang sebenarnya untuk digunakan oleh organisasi, dokumentasi dan pelatihan.

\section{Pemeliharaan Sistem}

Pada tahap akhir dari penelitian ini adalah melakukan pemeliharaan yang sudah berjalan untuk memastikan sistem berfungsi dengan baik, serta melakukan perbaikan pada sistem jika terjadi hal-hal meliputi corrective yaitu memperbaiki desain dan error pada program, adaptive yaitu memodifikasi sistem untuk beradaptasi dengan perubahan lingkungan, perfective yaitu melibatkan sistem untuk menyelesaikan masalah baru atau mengambil kesempatan (penambahan fitur) dan preventive yaitu menjaga sistem dari kemungkinan masalah di masa yang akan datang.

\section{ANALISIS SISTEM}

\section{Analisis Sistem Lama}

Karena Perpustakaan SMP/SMA Islam Al Azhar Kebayoran Baru sudah menggunakan SLiMS, kami pun tidak bisa mengganti sistem yang ada dengan SIAP (Sistem Informasi Perpustakaan) yang sudah dikembangkan sebelumnya oleh rekan-rekan Informatika yang lain secara menyeluruh. Oleh karena itu, kami hanya menggunakan database yang dimiliki oleh Perpustakaan SMP/SMA Islam Al Azhar Kebayoran Baru, yaitu database SLiMS. Data yang dimiliki oleh perpustakaan akan digunakan ke dalam sistem yang akan dikembangkan sebagai acuan dalam penelitian (Gambar 9). Dengan munggunakan DAO untuk melakukan manipulasi database perpustakaan sehingga mobile stock opname bisa dijalankan di Perpustakaan SMP/SMA Islam Al Azhar Kebayoran Baru.

Pada pengembangan sebelumnya, sudah dibuat Sistem Informasi Perpustakaan berbasis desktop (SIAP) dan aplikasi mobile stock opname menggunakan teknologi android dengan membuat database sendiri. SIAP adalah sistem informasi perpustakaan yang telah dikembangkan oleh Muhammad Syahid dan aplikasi mobile stock opname adalah pengembangan dari Arie Wahyu Triansyah.

Mobile application dirancang dengan sederhana, agar pustakawan dapat menggunakannya dengan baik. Karena inti dari poses stock opname hanya mencocokan data pada sistem dengan kondisi sebenarnya. Selain itu, saat stock opname pustakawan melakukan pemeriksaan koleksi yang jumlahnya sangat banyak ratusan bahkan ribuan. Hal tersebut membuat pustakawan harus lebih berkonsentrasi agar tidak ada data yang tertukar 
atau keliru, maka dibuatkanlah aplikasi mobile yang sederhana dan mudah digunakan.

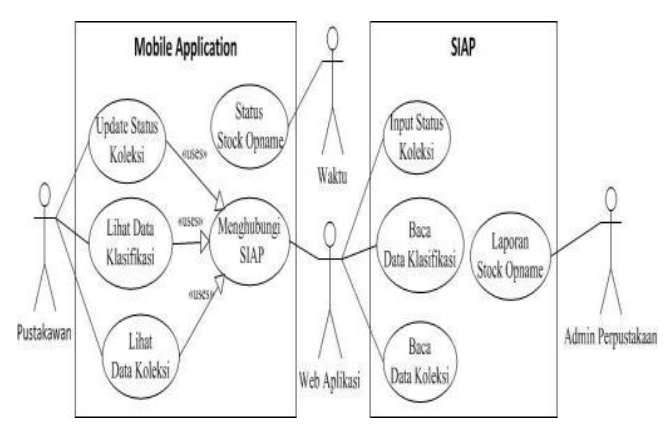

Gambar 9. Use Case Diagram Sistem Perpustakaan

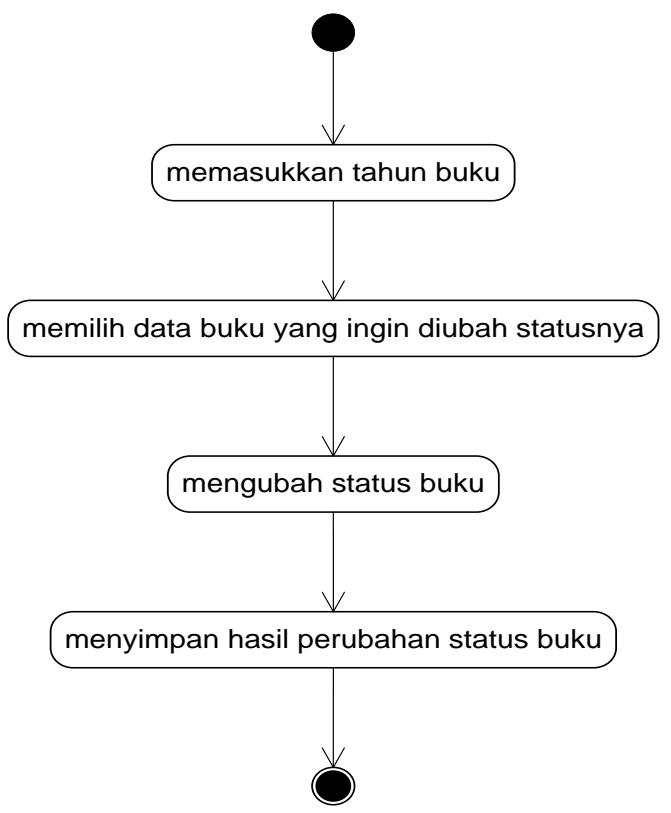

Gambar 10. Activity Diagram Mobile Stock Opname

\section{Perbandingan database SIAP dengan SliMS}

Di dalam database SIAP ada 5 tabel (Gambar 11). Sedangkan di dalam database SliMS yang digunakan di SMP/SMA Islam Al Azhar Kebayoran Baru ada 41 tabel dengan 6 tabel utama (Gambar 12).

Tabel stoke_take merupakan tabel yang berisi nama serta tanggal stock opname dilakukan, sedangkan tabel stock_take_item adalah tabel yang berisi item-item yang dilakukan stock opname dan status item tersebut, apakah ada, hilang, rusak, atau sudah tua. Tabel biblio berisi buku-buku sesuai judulnya, satu judul buku bisa terdiri dari banyak buku (item) sedangkan item adalah buku-buku yang ada di dalam perpustakaan.

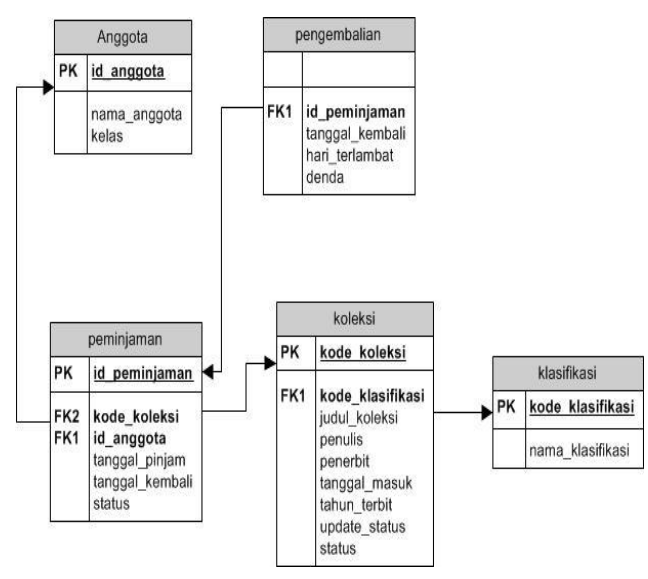

Gambar 11. Logical Record Structure SIAP

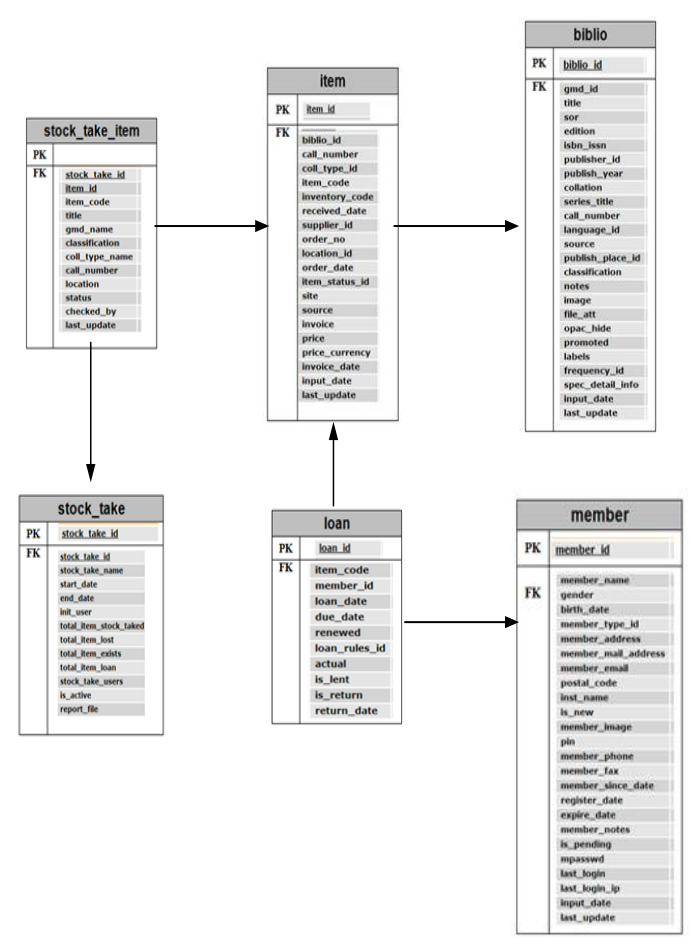

Gambar 12. Logical Record Structure SLiMS

Terdapat perbedaan antara database SIAP dan SliMS. Perbedaan nama tabel dan atribut-atribut didalam tabel, tetapi makna dan kegunaannya tidak jauh berbeda, seperti tabel koleksi pada database SIAP sama dengan tabel item pada SliMS.

Didalam pengkodean untuk item pada Perpustakaan SMP/SMA Islam Al Azhar Kebayoran Baru, terdapat dua kode, item_code dan call_number, item_code adalah nomor buku yang unik untuk setiap satuan buku sedangkan 
call_number adalah kode klasifikasi buku, dimana setiap judul buku mempunyai call_number yang lama, hanya di belakang call_number terdapat keterangan item tersebut adalah salinan keberapa dari buku yang berjudul sama. Contoh:

Judul : Sherlock Holmes

Penulis : Sir Arthur Conan Doyle

Klasifikasi Dewey : 8x3

Tahun masuk buku di Perpustakaan : 2013

Buku ke- dalam tahun tersebut : 104

Menurut data di atas, pengkodean itemnya menjadi Call number: 8x3 DOY s C1. 8x3 adalah nomor klasifikasi Dewey. DOY adalah tiga huruf pertama nama belakang penulis. s adalah huruf pertama dari judul buku. $\mathrm{C} 1$ adalah keterangan bahwa item tersebut adalah salinan atau copy pertama dari judul tersebut yang ada di perpustakaan.

Item code : B10413PA13. 13 adalah tahun masuk buku di Perpustakaan. 104 berarti item tersebut buku ke-104 di tahun 2013 yang didata dan masuk di Perpustakaan.

Di dalam database SliMS yang berhubungan dengan stock opname ada dua tabel yaitu tabel stock_take dan stock_take_item dimana tabel stock_take_item adalah detail dari tabel stock_take yang menyimpan data status dari tiap-tiap item buku. Sedangkan di dalam database SIAP, stock opname tidak dipisahkan tabelnya tetapi status buku langsung diubah di tabel koleksi.

\section{DESAIN DAN IMPLEMENTASI}

\section{Modifikasi DAO}

Sebelumnya rekan-rekan Informatika sudah membuat Sistem Informasi Perpustakaan berbasis desktop (SIAP) dan aplikasi mobile stock opname menggunakan teknologi android dengan membuat database sendiri, untuk implementasi mobile stock opname pada SliMS di Perpustakaan SMP/SMA Islam AlAzhar Kebayoran Baru, perlu mengganti database SIAP dengan database SliMS dan memodifikasi DAO dari stock opname. Di dalam package Model.DatabaseUtilities, class Model.DatabaseUtilities.java, koneksi database nya diubah dari db_siap menjadi database SliMS db_slim_meranti.
Langkah selanjutnya adalah membuat package Model.DAO.Slims berisi class KoleksiDAOSlims.java. Kelas ini akan diubah DAO yaitu perintah query koleksiByNoBuku dan package Model.Interface.Slims yang berisi class KoleksiNewSlims.java untuk menjalankan method koleksiByNoBuku.

\section{Desain Antar Muka}

Desain Antar muka disesuaikan dengan keinginan pustakawan sebagai user. Pada pengembangan sebelumnya, stock opname dilakukan berdasarkan klasifikasi buku, sedangkan pada Perpustakaan SMP/SMA Islam Al Azhar Kebayoran Baru, stock opname dilakukan berdasarkan tahun buku masuk ke perpustakaan tersebut. Gambar 13, 14, 15 memperlihatkan tampilan aplikasi stock opname.

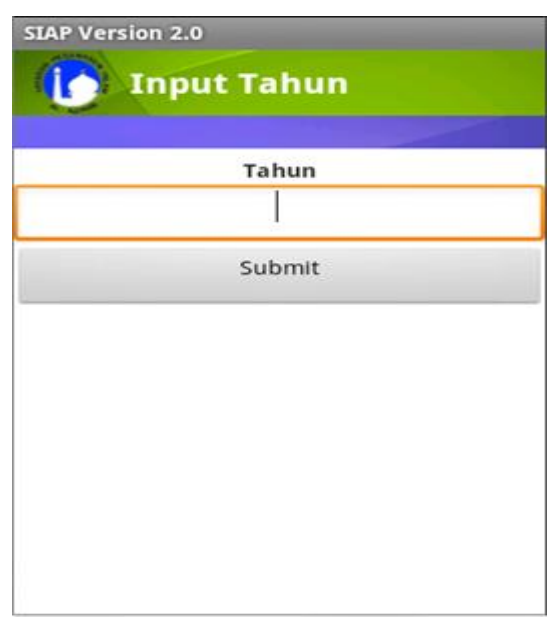

Gambar 13. Layar Input Tahun Buku

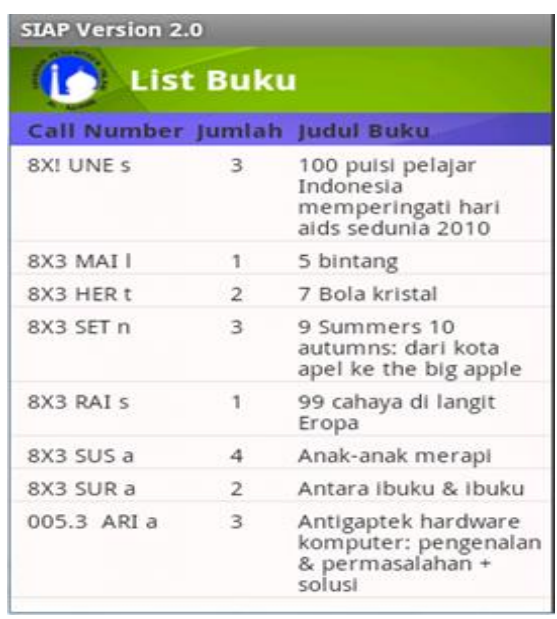

Gambar 14. Layar Daftar Buku 


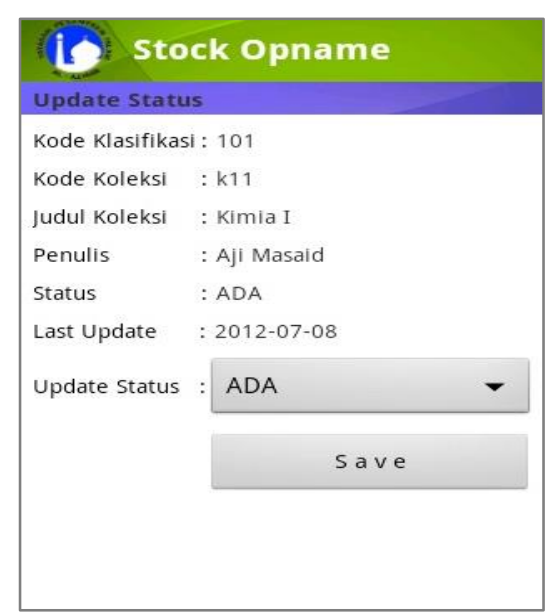

Gambar 15. Layar Stock Opname

\section{KESIMPULAN DAN SARAN}

Terdapat perbedaan antara database SIAP dan SliMS antara lain perbedaan nama tabel dan atribut-atribut didalam tabel, tetapi makna dan kegunaannya tidak jauh berbeda, seperti tabel koleksi pada database SIAP sama dengan tabel item pada SliMS. Pengkodean pada SliMS terdapat pada field item_code dan call_number sedangkan di database SIAP menggunakan kode_koleksi dan kode_klasifikasi.

Di dalam database SliMS yang berhubungan dengan stock opname ada dua table, yaitu tabel stock_take dan stock_take_item dimana tabel stock_take_item adalah detail dari tabel stock_take yang menyimpan data status dari tiaptiap item buku. Sedangkan di dalam database SIAP, stock opname tidak dipisahkan tabelnya tetapi status buku langsung diubah di tabel koleksi.

Untuk implementasi mobile stock opname pada SliMS di Perpustakaan SMP/SMA Islam AlAzhar Kebayoran Baru, database SIAP perlu diganti dengan database SliMS dan juga diperlukan modifikasi DAO dari stock opname. Langkah selanjutnya adalah mengubah perintah query disesuaikan dengan nama tabel dan atribut dalam database SliMS.

Dengan menggunakan mobile application yang terintegrasi dengan Senayan Library Management System (SLiMS) SMP/SMA Islam Al-Azhar, pustakawan tidak perlu lagi membuat print out semua data koleksi sebagai acuan. Data yang dibutuhkan sebagai acuan akan langsung tampil pada aplikasi mobile serta dapat langsung dilakukan perubahan status yang kemudian akan terkirim dan disimpan ke database melalui jaringan internet.

Saran yang dapat diberikan adalah mobile application yang dikembangkan baru terbatas pada modul yang digunakan oleh pustakawan, maka perlu dikembangkannya mobile application lain yang dapat digunakan untuk para siswa seperti mencari koleksi perpustakaan.

Sebaiknya modul stock opname lebih dibuat sesederhana mungkin, agar disesuaikan stock opname dengan menggunakan mobile. Pada proses bisnis stock opname, berita acara hasil stock opname perlu dibuat. Berita acara ini berisi data jumlah buku yang ada, hilang ataupun rusak. Hal ini perlu dilakukan untuk menjamin kebenaran data status buku hingga tanggal tertentu.

\section{DAFTAR PUSTAKA}

[1] M. Berger. Data Acces Object Pattern. 2005.

[2] M. O'Docherty. Object-Oriented Analysis and Design. England : John Wiley \& Sons Ltd. 2005.

[3] MR. Ridho. Panduan Penggunaan Aplikasi Software SENAYAN.

[4] HN. Safaat. Pemrograman Aplikasi Mobile Smartphone dan Tablet PC Berbasis Android. Bandung : Penerbit Informatika. 2012.

[5] AW. Triansyah. Integrasi Desktop Application dengan Mobile Application untuk Mengimplementasikan Modul Stock Opname pada Sistem Informasi Perpustakaan. Jakarta : Universitas Al Azhar Indonesia. 2012. 